\title{
Symptom clusters in obsessive-compulsive disorder (OCD): influence of age and age of onset
}

\author{
Agnieszka Butwicka $\cdot$ Agnieszka Gmitrowicz
}

Received: 10 February 2008/Accepted: 20 August 2009/Published online: 10 September 2009

(C) Springer-Verlag 2009

\begin{abstract}
Obsessive-compulsive disorder (OCD) is an ailment of heterogeneous nature. It is believed that the age of onset determines the subtype of juvenile OCD. The objective of our study was to evaluate the rates of symptoms' contents and the age of manifestation of the various OCD symptoms in adolescents and adults with early and late onset of disorder. Both authors independently reviewed the medical charts of patients treated for OCD between 1999 and 2007 in a psychiatric university hospital. Patients were evaluated using the Yale-Brown obsessive-compulsive scale check list (Y-BOCS). The patients were grouped as adolescents (group 1), adults with late onset (group 2) and adults with early onset (group 3). Chi2 was used for nominal variables and the non-parametric Kruskal-Wallis ANOVA for continuous comparisons due to deviations from normality of distribution. A total of 132 patients were enrolled in the study (44 group 1, 43 group 2 and 45 group $3)$. There were no differences in gender distribution. Religious, sexual and miscellaneous obsessions were more frequent and somatic less frequent in group 1 than in group 2. Contamination compulsions were most seldom found in group 1. Cleaning obsessions were more frequent in group 3 than in group 1 . Checking were the rarest and miscellaneous, the most often compulsion among adolescents in comparison to other groups. The symptoms' content in adolescents differed from those observed in adult, both with early and later onset of the disease. The age at onset influences the rates of adult patients' compulsions.
\end{abstract}

\footnotetext{
A. Butwicka $(\bowtie) \cdot$ A. Gmitrowicz

Department of Adolescent Psychiatry,

Medical University of Lodz, Lodz, Poland

e-mail: agnieszka.butwicka@gmail.com
}

Keywords Obsessions - Compulsions · Adults · Adolescents · Age of onset

\section{Introduction}

Obsessive-compulsive disorder (OCD) is heterogeneous in nature and depends for example on the patient's sex, coexisting disorders, family history and age of onset $[4,5$, $7,8,11-13,22]$.

In particular, the differences in symptomatology between pediatric and adult patients with OCD are of interest for clinicians [14]. In adolescent samples, the most common categories of obsession are reported as follows: contaminations, fear of illness/fate, exactness/symmetry and religiosity/scrupulousness [23]. In studies on adults similar frequencies of these contents were found. Sexual and aggressive obsessions were more common in adult groups $[3,17,18]$. The most common contents of compulsion in adolescents were (starting from the most frequent): cleaning, repeating and checking [23, 26]; in adults: checking, cleaning $[18,19,28]$ and counting $[17,18]$.

Unfortunately, direct comparisons of pediatric and adult populations using similar methodology are scarce. The available data shows higher frequency of aggressive obsessions in the children/adolescent group than in the adult group. Religious and sexual obsessions were predominantly associated with the adolescent period [8].

Researchers postulate that juvenile OCD is a developmental subtype determining its course throughout adult life $[5,7,15,20,27]$. Therefore, age of onset might also influence OC-profile. There is evidence that adult patients with early onset (EO) differ clinically from those with late onset of OCD (LO). For example, EO patients had a more premature onset of sub-clinical symptoms, a more 
aggressive course of disease, greater number [21] and severity of symptoms. They also exhibited higher frequency of tic-like compulsions, sensory phenomena and comorbid tic disorders [20]. Moreover, EO patients, compared to LO, had worse short-term therapeutic response to clomipramine and selective serotonin reuptake inhibitors [20] or required a greater number of therapeutic regimens with different medications [5]. These findings suggested that early onset obsessive-compulsive disorder (EOCD) represents a more severe subtype of OCD [5]. However, there is no consensus with regard to the specific content of the symptoms associated with EOCD [5] and regarding symptoms' stability over time.

The purpose of this study was twofold. First, to investigate differences in OCD symptoms between adolescent versus adult patients and second between EOCD versus LOCD groups. This is the first report of its type concerning Polish inpatients and, to the authors' knowledge, the first such report in English from any eastern European country.

\section{Method}

The Institutional Review Board approved this study. This is only a retrospective chart review of inpatients treated for OCD in the period 1999-2007, in psychiatric units of the Central Clinic Hospital of the Medical University of Lodz. Information on outpatients with OCD was not available. Both authors reviewed the medical charts independently. Any discrepancies were resolved by best estimate case conferences. All patients were diagnosed during nonstructured psychiatric interview by board certified psychiatrists or child and adolescent psychiatrists.

Inclusion criteria were set as follows: a fulfilment of both ICD-10 [24] and DSM-IV [2] criteria of OCD, age of less than 60 years, and available full medical record including Y-BOCS $[9,10]$. The patients were divided into three groups: adolescents (group 1), adults (aged 19 years or older) with onset at 18 years or later (group 2) and adults with onset prior to 18 years (group 3). The groups' division was similar to those made by Sobin et al. [21]. According to the relevant literature, "the age of onset" was defined as the age that the patient, or family member, remembered as the beginning of obsessive-compulsive symptoms [20].

A classification of symptoms detailed in Y-BOCS was used during the clinical interview at the first hospitalization due to OCD. Psychiatric comorbid disorders were also diagnosed according to the International Classification of Diseases, 10th revision [24]. Comorbidity was allowed for inclusion in the study. Reliability between the interviewers could not be verified, due to the retrospective character of the study. Nominal data are presented as percentages and were compared using $\mathrm{Chi}^{2}$, Yates corrected $\mathrm{Chi}^{2}$ or two-tailed Fisher's exact test depending on group size. Ordinal variables are given as medians and interquartile ranges (IQR). These were compared using the non-parametric Kruskal-Wallis ANOVA with a post-hoc, Bonferroni corrected Mann-Whitney $U$ test, due to the deviations from normality of distribution. A $P$ level of less than 0.05 was considered as statistically significant. Statistica 7.0 statistical package (Statsoft, Tulsa, USA) was used for calculations.

\section{Results}

The studied group consisted of 132 patients ( 50 females, 82 males). All patients with a diagnosis of OCD were included in the analyzed groups, and the authors found no reasons to perform any exclusion. Table 1 shows the main group characteristics.

Educational level was: primary $(n=58,45 \%)$, vocational $(n=17,13 \%)$, secondary $(n=37,28 \%)$ and postsecondary $(n=20,15 \%)$.

The sample was divided into the following subgroups: adolescents $(n=44)$, adults with onset at 18 years of age or later $(n=43)$ and adults with onset prior to 18 years $(n=45)$. The difference in the gender distribution did not reach statistical significance $(P=0.0855)$ with males slightly overrepresented in the first and third group. The time from initial symptoms to diagnosis was the longest $(P<0.05)$ in adults with EOCD. There were no differences between the groups in symptom severity and the number of symptoms according to YBOCS (Table 1).

Obsessions and compulsions within the three subgroups are listed in Table 2.

Patients with coexisting psychiatric diagnoses $(n=59$; $45 \%$ ) were not excluded from the analysis. Comorbidities of the three subgroups are listed in Table 3.

\section{Discussion}

The strength of this study, in comparison with others on this topic, is that it is based on samples containing adolescent and adult patients (the latter with early and late onset). In the light of knowledge that religion and other cultural influences are associated with the presentation of obsessive-compulsive symptoms $[1,6,16]$, the setting of the study in Poland is also a valuable asset due to its novelty and the paucity of data on patients in Eastern European countries. Some limitations need to be discussed. The main limitation is the retrospective character of the analysis and the non-structured, non-standardized interview by several unknown physicians which reduces the validity of the data, especially concerning data on 
Table 1 General characteristics and comparison of sex distribution, time variables (values are given in years), number of symptoms and symptoms' severity according to YBOCS in the analyzed groups

\begin{tabular}{|c|c|c|c|c|c|c|c|c|}
\hline & \multicolumn{2}{|c|}{$\begin{array}{l}\text { Children and adolescents } \\
(n=44)(\%)\end{array}$} & \multicolumn{2}{|c|}{$\begin{array}{l}\text { Adults with onset } \\
\text { at age } \geq 18 \text { years }(n=43)(\%)\end{array}$} & \multicolumn{3}{|c|}{$\begin{array}{l}\text { Adults with onset } \\
\text { at age }<18 \text { years }(n=45)(\%)\end{array}$} & $P$ value \\
\hline \multicolumn{9}{|c|}{ Patients' sex } \\
\hline Males & $31(70)$ & & $21(49)$ & & $30(67)$ & & & 0.086 \\
\hline \multirow[t]{2}{*}{ Females } & $13(30)$ & & $22(51)$ & & $15(33)$ & & & \\
\hline & & Mean \pm SD & Median (IQR) & Mean \pm SD & Median (IQR) & Mean \pm SD & Median (IQR) & $P$ value \\
\hline \multicolumn{9}{|c|}{ Time variables } \\
\hline \multicolumn{2}{|c|}{ Age at diagnosis } & $13.7 \pm 2.6$ & $13.5(12-16)$ & $30.0 \pm 9.5$ & $26(24-34)$ & $19.5 \pm 0.9$ & $19(16-21)$ & $<0.001$ \\
\hline \multicolumn{2}{|c|}{ Age at initial symptoms } & $12.8 \pm 2.9$ & $13(11-15)$ & $27.4 \pm 9.0$ & $24(22-31)$ & $14.4 \pm 3.1$ & $15(12-17)$ & $<0.001$ \\
\hline \multicolumn{2}{|c|}{ Duration of treatment } & $1.8 \pm 2.3$ & $1.0(0.0-3.0)$ & $3.6 \pm 0.7$ & $2(0-4)$ & $5.7 \pm 6.9$ & $4(1-8)$ & 0.004 \\
\hline \multicolumn{2}{|c|}{$\begin{array}{l}\text { Duration of disease (from initial } \\
\text { symptoms to evaluation) }\end{array}$} & $2.8 \pm 2.7$ & $2.0(1.0-4.0)$ & $6.2 \pm 0.9$ & $5(2-10)$ & $10.8 \pm 8.5$ & $9(5-13)$ & $<0.001$ \\
\hline \multicolumn{2}{|c|}{$\begin{array}{l}\text { Time from initial symptoms } \\
\text { to diagnosis of OCD }\end{array}$} & $0.9 \pm 1.2$ & $0 *(0.0-2.0)$ & $2.6 \pm 0.7$ & $0 *(0-4)$ & $5.1 \pm 6.0$ & $4(0-8)$ & 0.001 \\
\hline \multicolumn{9}{|c|}{ Number of symptoms } \\
\hline \multicolumn{2}{|c|}{ No of obsessions } & $1.38 \pm 1.08$ & $1(1-2)$ & $1.09 \pm 0.95$ & $1(0-2)$ & $1.47 \pm 1.06$ & $1(1-2)$ & 0.26 \\
\hline \multicolumn{2}{|c|}{ No of compulsions } & $1.76 \pm 1.13$ & $2(1-3)$ & $1.60 \pm 1.35$ & $1(1-3)$ & $2.16 \pm 1.58$ & $2(1-3)$ & 0.27 \\
\hline \multicolumn{9}{|c|}{ Y-BOCS scores } \\
\hline \multicolumn{2}{|c|}{ Obsessions } & $7.7 \pm 2.5$ & $8.0(5.0-10.0)$ & $9.8 \pm 6.8$ & $9.5(4.0-15.5)$ & $11.5 \pm 4.9$ & $11.5(8.0-15.0)$ & 0.74 \\
\hline \multicolumn{2}{|c|}{ Compulsions } & $12.7 \pm 4.6$ & $10.0(10.0-18.0)$ & $13.7 \pm 4.5$ & $12.5(10.5-17.0)$ & $10.0 \pm 2.8$ & $10.0(8.0-12.0)$ & 0.54 \\
\hline
\end{tabular}

IQR interquartile range; $S D$ standard deviation

$*<1$ year

coexisting disorders. A relatively small group of adolescent patients made it impossible to divide them into two distinct groups concerning age of onset as with the adults. Further, several confounding factors (e.g., comorbidity, medication) could not be controlled, and for adolescents no CY-BOCS was used.

However, the presented study was based on OCD symptoms according to systematic Y-BOCS application $[9,10]$. This was a consequence of the regular diagnostic approach used in Poland. The CY-BOCS was not validated in the Polish population throughout the analyzed period.

\section{Comparison between adolescents and adults}

The presented data could show some differences in the content of symptoms between adolescent and adult groups. They are partially in accordance with available literature on the subject, with thought rituals, from the Y-BOCS miscellaneous category (excessive listmaking, need to tell, ask, or confess, need to touch, tap, or rub, rituals involving blinking or staring, ritualized eating behaviors, trichotillomania, etc.), reported to be characteristic in childhood, being the best example [25]. Sexual and religious obsessions were reported to be the most frequent in adolescents [8], and this was also observed in the studied population. We did not note, however, any age-dependent variability of aggressive obsessions. In the studied group somatic and contamination obsessions as well as cleaning/washing and checking compulsions were rarely observed in younger patients. Several symptoms, such as cleaning/washing compulsions, similar to other reports turned out to be among the most frequently exhibited by adolescents, although they were less frequent than in adults [8]. Other symptoms, for example aggressive obsessions, which were the most frequent in younger patients, were equally frequent in adults.

\section{Comparison between adult-subgroups}

We are aware that the arbitrarily chosen cut-off point of 18 years in this study, which was, however, previously used by other authors [21] might be not the best way to define EOCD. Mathis et al. [13] observed that no age threshold could clearly stratify the sample into homogeneous subgroups. Cluster analyses used in that study revealed that differences started to emerge at the age of 10 and were more pronounced at the age of 17 , suggesting that these might have been suitable cut-off points for a sample to be studied [13]. This approach, however, may be burdened by the cultural and epidemiologic background, since the quoted study was performed on a sample of Brazilian children and adolescents, which may differ in symptoms 
Table 2 Obsessions and compulsions within the three subgroups

* $P<0.06$ for comparison between adult with late and early onset

** $P<0.06$ for comparison between adolescents group and adult with early onset

a Significance between adolescents group and adult with late onset $(P<0.05)$

b Significance between adult with late and early onset $(P<0.05)$

c Significance between adolescents group and adult with early onset $(P<0.05)$

Table 3 The comorbidities within the three subgroups

* $P<0.06$ for comparison between adult with late and early onset

** $P<0.06$ for comparison between adolescents group and adult with early onset

a Significance between adolescents group and adult with late onset $(P<0.05)$

b Significance between adult with late and early onset $(P<0.05)$

c Significance between adolescents group and adult with early onset $(P<0.05)$

\begin{tabular}{lccll}
\hline & $\begin{array}{l}\text { Adolescents } \\
(n=44)(\%)\end{array}$ & $\begin{array}{l}\text { Adults with onset } \\
\text { at age } \geq 18 \text { years } \\
(n=43)(\%)\end{array}$ & $\begin{array}{l}\text { Adults with onset } \\
\text { at age }<18 \text { years } \\
(n=45)(\%)\end{array}$ & $P$ value \\
\hline Obsessions & $38(86)$ & $37(86)$ & $36(80)$ & 0.62 \\
Aggressive & $15(34)$ & $18(42)$ & $13(29)$ & 0.44 \\
Contamination & $7(16)$ & $17(40)$ & $18(40)$ & $0.02^{\mathrm{a}, \mathrm{c}}$ \\
Sexual & $9(20)$ & $1(2)$ & $3(7)$ & $0.01^{\mathrm{a}}$ \\
Hoarding/saving & $2(5)$ & $3(7)$ & $3(7)$ & 0.87 \\
Religious & $12(27)$ & $1(2)$ & $5(11)$ & $0.003^{\mathrm{a}}$ \\
Symmetry/exactness & $10(23)$ & $5(12)$ & $12(27)$ & 0.20 \\
Somatic & $3(7)$ & $13(30)$ & $7(16)$ & $0.02^{\mathrm{a}, * *}$ \\
Miscellaneous & $16(36)$ & $4(9)$ & $44(98)$ & $0.005^{\mathrm{a}, * *}$ \\
Compulsions & $40(91)$ & $34(79)$ & $30(67)$ & $0.02^{\mathrm{b}}$ \\
Cleaning/washing & $17(39)$ & $20(47)$ & $24(53)$ & $0.02^{\mathrm{c}, *}$ \\
Checking & $10(23)$ & $19(44)$ & $18(40)$ & $0.01^{\mathrm{a}, \mathrm{c}}$ \\
Repeating rituals & $20(45)$ & $11(26)$ & $10(22)$ & 0.14 \\
Counting & $4(9)$ & $7(16)$ & $12(27)$ & $3(7)$ \\
Ordering/arranging & $8(18)$ & $7(16)$ & $12(27)$ & 0.24 \\
Hoarding/collecting & $0(0)$ & $3(7)$ & $9(21)$ & 0.43 \\
Miscellaneous & $24(55)$ & & 0.21 \\
\hline
\end{tabular}

\begin{tabular}{lllll}
\hline & $\begin{array}{l}\text { Adolescents } \\
(n=44)(\%)\end{array}$ & $\begin{array}{l}\text { Adults with onset } \\
\text { at age } \geq 18 \text { years } \\
(n=43)(\%)\end{array}$ & $\begin{array}{l}\text { Adults with onset } \\
\text { at age }<18 \text { years } \\
(n=45)(\%)\end{array}$ & $P$ value \\
\hline Personality disorder & $0(0)$ & $12(28)$ & $12(27)$ & $0.0007^{\mathrm{a}, \mathrm{c}}$ \\
Depressive episode & $5(11)$ & $4(9)$ & $4(9)$ & 0.92 \\
Mental retardation & $3(7)$ & $2(5)$ & $3(7)$ & 0.91 \\
Psychoactive substance use abuse & $0(0)$ & $6(14)$ & $1(2)$ & $0.008^{\mathrm{a}}$ \\
Tic disorders & $5(11)$ & $1(2)$ & $0(0)$ & $0.03^{* *}$ \\
Schizophrenia & $1(2)$ & $3(7)$ & $2(4)$ & 0.57 \\
Non-OCD Anxiety disorders & $1(2)$ & $1(2)$ & $0(0)$ & 0.59 \\
Delusional disorders & $1(2)$ & $1(2)$ & $1(2)$ & 0.79 \\
Schizotypal disorder & $1(2)$ & $1(2)$ & $2(4)$ & 1.00 \\
Adjustment disorders & $0(0)$ & $0(0)$ & $2(4)$ & 0.14 \\
Schizoaffective disorders & $0(0)$ & $0(0)$ & $0(0)$ & 0.14 \\
Eating disorders & $2(5)$ & $0(0)$ & $0(0)$ & 0.14 \\
Conduct disorder & $1(2)$ & $0(0)$ & $1(2)$ &
\end{tabular}

presentation from their European counterparts, although hyperkinetic children from both ethnological backgrounds show similar psychopathological profiles [19].

No differences were found between EOCD and LOCD in adults with regard to obsessions. However, EO adult patients presented more frequent compulsions than LO patients, with a tendency to exhibit more washing and cleaning, even more than pediatric patients. The time from the initial symptoms to diagnosis was the longest in EO adult patients, which differs from findings of Sobin et al. [21]. This difference could be due to unrecognized cases of OCD in the past, which might explain the much shorter time from the initial symptoms to a diagnosis in the children and adolescent group. Although Millet et al. [15] observed that gradual appearance of symptoms occurred more often in EOCD, while a sudden onset of disorder was characteristic of LO patients.

Comparison of comorbidities

Rosario-Campos et al. found a higher mean number of comorbid diagnoses in EO than in LO adult patients. Comorbid chronic tic disorders and Tourette's disorder 
were also more frequent in the EO group. A recent study of Mathis et al. [13] showed that earlier age of onset was associated with a higher probability of tic, anxiety, somatoform, eating and impulse-control disorders. In our sample tic disorders were slightly more frequent $(P<0.06)$ in adolescents, although there was no difference between LO and EO adults that was probably caused by small amount of tic disorders' diagnosis in adult patients (only one patient with tic disorders in adults). Mental and behavioural disorders due to psychoactive substance use were more frequent in adolescent that in LO adult. There was no difference in amount of these disorders between adolescents and EO adults. Existing differences in amount of personality disorder between adolescents and adults were due to ICD-10 criteria.

In conclusion, this study based on a direct comparison of adolescent patients with adults has many methodological shortcomings, but showed that there exist some differences between the symptom clusters of OCD of both groups. Furthermore, it elucidated that the symptoms may differ depending on the patient's age and the duration of OCD.

The question of whether these differences between adolescent and adult samples represent a true subtype or only the developmental progression of symptoms during the natural course of OCD and modified by environmental influences deserves further studies.

However, we believe that due to a paucity of OCD data discussing the issue of content of symptoms, this work offers some additional possibilities for discussion and further studies.

Acknowledgments We would like to acknowledge Wojciech Fendler MD for statistical advice and help in preparation of the manuscript.

\section{References}

1. Abramowitz JS, Deacon BJ, Woods CM, Tolin DF (2004) Association between Protestant religiosity and obsessive-compulsive symptoms and cognitions. Depress Anxiety 20:706

2. American Psychiatric Association (APA) (1994) Diagnostic and statistical manual of mental disorders, 4th edn. APA, Washington, DC

3. Dowson JH (1977) The phenomenology of severe obsessivecompulsive disorders. Br J Psychiatry 131:75-78

4. Eichstedt JA, Arnold SL (2001) Childhood-onset obsessivecompulsive disorder: a tic-related subtype of OCD? Clin Psychol Rev 21:137-158

5. Fontenelle LF, Mendlowicz MV, Marques C, Versiani M (2003) Early- and late-onset obsessive-compulsive disorder in adult patients: an exploratory clinical and therapeutic study. J Psychiatric Res 37:127-133

6. Fontenelle LF, Mendlowicz MV, Marques C, Versiani M (2004) Trans-cultural aspects of obsessive-compulsive disorder: a description of a Brazilian sample and a systematic review of international clinical studies. J Psychiatr Res 38:403-411
7. Geller D, Biederman J, Jones JE, Park K, Schwartz S, Shapiro S, Coffey B (1998) Is juvenile obsessive-compulsive disorder a developmental subtype of the disorder? A review of the pediatric literature. J Am Acad Child Adolesc Psychiatry 37:420-427

8. Geller DA, Biederman J, Faraone S, Agranat A, Cradock K, Hagermoser L, Kim G, Frazier J, Coffey BJ (2001) Developmental aspects of obsessive compulsive disorder: findings in children, adolescents, and adults. J Nerv Ment Dis 189:471-477

9. Goodman WK, Price LH, Rasmussen SA, Mazure C, Fleischmann RL, Hill CL, Heninger GR, Charney DS (1989) Yale-Brown obsessive compulsive scale (Y-BOCS): Part I. Development, use, and reliability. Arch Gen Psychiatry 46:1006-1011

10. Goodman WK, Price LH, Rasmussen SA, Mazure C, Delgado P, Heninger GR, Charney DS (1989) Yale-Brown obsessive compulsive scale (Y-BOCS): Part II. Validity. Arch Gen Psychiatry 46:1012-1016

11. Leckman JF, Grice DE, Boardman J, Zhang H, Vitale A, Bondi C, Alsobrook J, Peterson BS, Cohen DJ, Rasmussen SA, Goodman WK, McDougle CJ, Pauls DL (1997) Symptoms of obsessive-compulsive disorder. Am J Psychiatry 154:911-917

12. Leckman JF, Zhang H, Alsobrook JP, Pauls DL (2001) Symptom dimensions in obsessive-compulsive disorder: toward quantitative phenotypes. Am J Med Genet 8:28-30

13. Mathis MA, do Rosario MC, Diniz JB, Torres AR, Shavitt RG, Ferrão YA, Fossaluza V, Bragança Pereira CA, Miguel EC (2008) Obsessive-compulsive disorder: influence of age at onset on comorbidity patterns. Eur Psychiatry 23:187-194

14. McKay D, Piacentini J, Greisberg S, Graae F, Jaffer M, Miller J (2006) The structure of childhood obsessions and compulsions: dimensions in an outpatient sample. Behav Res Ther 44:137-146

15. Millet B, Kochman F, Gallarda T, Krebs MO, Demonfaucon F, Barrot I, Bourdel MC, Olié JP, Loo H, Hantouche EG (2004) Phenomenological and comorbid features associated in obsessive-compulsive disorder: Influence of age of onset. J Affect Disord 79:241-246

16. Okasha A, Saad A, Khalil AH, el Dawla AS, Yehia N (1994) Phenomenology of obsessive-compulsive disorder: a transcultural study. Compr Psychiatry 35:191-197

17. Rachman S, Hodgson R (1980) Obsessions and compulsions. Prentice-Hall, Englewood Cliffs

18. Rasmussen SA, Tsuang MT (1986) Clinical characteristics and family history in DSM-III obsessive-compulsive disorder. Am J Psychiatry 143:317-322

19. Roessner V, Becker A, Rothenberger A, Rohde LA, Banaschewski $\mathrm{T}$ (2007) A cross-cultural comparison between samples of Brazilian and German children with ADHD/HD using the Child Behavior Checklist. Eur Arch Psychiatry Clin Neurosci 257:353-359

20. Rosario-Campos MC, Leckman JF, Mercadante MT, Shavitt RG, Prado HS, Sada P, Zamignani D, Miguel EC (2001) Adults with early-onset obsessive-compulsive disorder. Am J Psychiatry 158:1899-1903

21. Sobin C, Blundell ML, Karayiorgou M (2000) Phenotypic differences in early- and late-onset obsessive-compulsive disorder. Compr Psychiatry 41:373-379

22. Storch EA, Lack CW, Merlo LJ, Geffken GR, Jacob ML, Murphy TK, Goodman WK (2007) Clinical features of children and adolescents with obsessive-compulsive disorder and hoarding symptoms. Compr Psychiatry 48:313-318

23. Swedo S, Rapoport J, Leonard H, Lenane M, Cheslow D (1989) Obsessive-compulsive disorder in children and adolescents: clinical phenomenology of 70 consecutive cases. Arch Gen Psychiatry 46:335-341

24. International Statistical Classification of Diseases and Related Health Problems 10th Revision (1992) Classification of Mental and Behavioral Disorders. Clinical descriptions and diagnostic guidelines. World Health Organization, Geneva 
25. Thomsen P (1993) Obsessive-compulsive disorder in children and adolescents: self-reported obsessive-compulsive behaviour in pupils in Denmark. Acta Psychiatr Scand 88:212-217

26. Toro J, Cervera M, Osejo E, Salamero M (1992) Obsessivecompulsive disorder in childhood and adolescence: a clinical study. J Child Psychol Psychiatry Allied Disciplines 33:10251037
27. Tukel R, Ertekin E, Batmaz S, Alyanak F, Sözen A, Aslantaş B, Atli $\mathrm{H}$, Ozyildirim I (2005) Influence of age of onset on clinical features in obsessive-compulsive disorder. Depress Anxiety 21:112-117

28. Welner A, Reich T, Robins E, Fishman R, Van Doren T (1976) Obsessive-compulsive neurosis: record follow-up and family studies. Compr Psychiatry 17:527-539 